\title{
Comparative effect and safety of verapamil in keloid and hypertrophic scar treatment: a meta-analysis
}

\section{Zhouna Li \\ Zhehu Jin}

Department of Dermatology, Yanbian University Affiliated hospital, Yanji, Jilin, People's Republic of China
Correspondence: Zhehu Jin Department of Dermatology, Yanbian University Affiliated Hospital, I 327 Juzi Street, Yanji, Jilin I33000, People's Republic of China

Tel +864332660009

Email huzejinjz@I26.com
This article was published in the following Dove Press journal:

Therapeutics and Clinical Risk Management

9 November 2016

Number of times this article has been viewed

Background: Keloids and hypertrophic scars are the most common types of pathological scarring. Traditionally, keloids have been considered as a result of aberrant wound healing, involving excessive fibroblast participation that is characterized by hyalinized collagen bundles. However, the usefulness of this characterization has been questioned. In recent years, studies have reported the appropriate use of verapamil for keloids and hypertrophic scars.

Methods: Searches were conducted on the databases Medline, Embase, Cochrane, PubMed, and China National Knowledge Infrastructure from 2006 to July 2016. State12.0 was used for literature review, data extraction, and meta-analysis. Treatment groups were divided into verapamil and nonverapamil group. Nonverapamil group includes steroids and intense pulsed light (IPL) therapy. Total effective rates include cure rate and effective rate. Cure: skin lesions were completely flattened, became soft and symptoms disappeared. Efficacy: skin lesions subsided, patient significantly reduced symptoms. Inefficient definition of skin was progression free or became worse. Random-effects model was used for the meta-analysis.

Results: Six studies that included 331 patients with keloids and hypertrophic scars were analyzed. Analysis of the total effective rate of skin healing was performed. The total effective rates in the two groups were $54.07 \%$ (verapamil) and $53.18 \%$ (nonverapamil), respectively. The meta-analysis showed that there was no difference between the two groups. We also compared the adverse reactions between the verapamil treatment group and the steroids treatment group in two studies, and the result indicated that the verapamil group showed less adverse reactions.

Conclusion: There were no differences between the application of verapamil and nonverapamil group in keloids and hypertrophic scars treatment. Verapamil could act as an effective alternative modality in the prevention and treatment of keloid and hypertrophic scars. A larger number of studies are required to confirm our conclusion.

Keywords: keloids, hypertrophic scars, verapamil, steroids, IPL

\section{Introduction}

Abnormal wound healing easily leads to the occurrence of keloids and hypertrophic scars. ${ }^{1,2}$ Keloids and hypertrophic scars in general, belong to cutaneous pathological scars. ${ }^{3}$ Their appearance is caused by the proliferation of fibroblast cells and the formation of a large extracellular matrix; and the development is characterized by excessive collagen synthesis and deposition. ${ }^{4}$ They do not regress with time and usually recur after surgical excision. Nowadays, there are drugs and therapies available for keloids and hypertrophic scar therapy, but they are also faced by great challenges in prophylaxis and therapy. There is no satisfactory universal method that is suitable for the treatment of all..$^{5-7}$ 
In 1992, Lee first reported the use of the calcium channel blocker verapamil for keloid treatment and immediately attracted the attention of clinicians. With the progress of this first study, the finding was also confirmed in cell biology experiments, as well as in animal and human trials. Verapamil has been proven to increase the synthesis of procollagenase in keloids, hypertrophic scars, and normal cultured fibroblasts. It also leads to depolymerization of actin filaments, cell conformational changes, and apoptosis, and ultimately, to reduce production of fibrous tissue. ${ }^{8}$ Boggio et $\mathrm{al}^{9}$ confirmed that verapamil is involved in the process of wound healing. They found that $50 \mu \mathrm{M}$ verapamil was an excellent choice as a scar modulator. Moreover, it was also used to avoid the development of keloids and hypertrophic scars after plastic surgery. For example, Copcu et $\mathrm{al}^{10}$ reported that surgery combined with the application of verapamil may be effective in the prevention and treatment of keloids. To investigate whether the topical application of verapamil after surgical repair of nerves could inhibit the formation of excessive scar tissue in vivo, Han et a ${ }^{11}$ transected the right sciatic nerve of adult rats. The stoma was wrapped in gelfoam and soaked in verapamil solution for 4 weeks. In vivo application of verapamil inhibited the secretion of extracellular matrix from fibroblasts, increased the number of myelinated axons and the total number of axons, and suppressed type I and III collagen secretion. The result showed that verapamil reduced the formation of keloid tissue and promoted axon growth after peripheral nerve repair. In another study, verapamil was found to inhibit interleukin- 6 and vascular endothelial growth factor production in primary culture of keloid fibroblast. ${ }^{12}$ Glucocorticoids have been applied for the therapy of keloids and hypertrophic scars since the beginning of 1960 and are currently recognized as the first-line drugs for keloid treatment and second-line drugs for hypertrophic scars. A large number of drugs can be used in the treatment of keloids and hypertrophic scars, such as hydrocortisone hydrochloride, methylprednisolone, and dexamethasone. Their mechanism of action may be through suppressing the level of the proliferation of fibroblasts of keloids and hypertrophic scars and inhibition of collagen synthesis, as well as through the increase in collagenase production and a reduction in the level of collagenase inhibitors. ${ }^{13}$ Nevertheless, today the side effects of glucocorticoids lead to more restrictions for their utilization.

Radiation therapy may be applied as a main or adjuvant treatment option after surgery of abnormal keloids tissue. ${ }^{14}$ It caused a rapid decrease in the immune function of the patients and led to obvious side effects. Thus, the application of radiation in such cases had to be limited. Laser therapy, the use of different wavelengths of laser light, has been used for the treatment of keloids and hypertrophic scars for more than 20 years. ${ }^{15,16}$ However, the administration of this therapy type results in the destruction of not only diseased but also of normal tissues, leading to adverse reactions. Furthermore, its clinical application is more expensive and subjected to restrictions.

In this meta-analysis, we compared the impacts of the treatment with verapamil and other therapeutic methods in keloids and hypertrophic scars. Some studies have confirmed that the combination of verapamil with other methods may have more pronounced effects in the treatment of keloids and hypertrophic scars. For example, patients treated with excision followed by the topical application of silicone alone or in combination with intralesional verapamil manifested increased cure rates. ${ }^{17}$ However, longer time and more studies will be necessary to confirm these findings. Therefore, the current meta-analysis can provide an adequate basis and prospects in the selection of the most appropriate options for the treatment of keloids and hypertrophic scars.

\section{Methods Publication search}

The databases Medline, Embase, Cochrane, PubMed, Elsevier, and China National Knowledge Infrastructure were searched using the keywords "keloid", "hypertrophic scars", "calcium channel blocker", "verapamil", "steroids", and "physical therapy". The most recent research update was published on February 24, 2016. We used these search criteria to select relevant reading topics, abstracts, and full-text papers.

\section{Inclusion and exclusion criteria}

The inclusion criteria were as follows: 1) research design: research articles in published Chinese and English of investigations on verapamil application as compared with that of other methods for the treatment of keloids and hypertrophic scars; 2) research object: verapamil administration compared with other therapeutic methods in keloid and hypertrophic scars; 3 ) interventions: experiment group, verapamil treatment group; control group, group in which other drugs or physical therapy were used; 4) total effective rate: cure rate and effective rate were included. Cure: skin lesions were completely flattened, became soft and symptoms disappeared. Efficacy: skin lesions subsided, patient significantly reduced symptoms. Inefficient definition of skin was progression free or became worse. Invalidity: pain, itching, and other symptoms were not changed or relieved. Scar texture and size had changed slightly or scars recurred in the observation time. 
The exclusion criteria were as follows: 1) animal or cell biology research; 2) absence of verapamil treatment of keloids and hypertrophic scars; 3 ) lack of clarity or relation of the experimental results to the meta-analysis.

\section{Data extraction}

Two personnel extracted data from the search results strictly following the inclusion and exclusion criteria and the key words requirements. Disagreements were resolved through discussions and the achievement of consensus. The data extracted from each study included the name of the first author, year of publication, treatment time, number of cases, drug doses, clinicopathological parameters, and case collection period. Adverse reactions include aches, skin hyperpigmentation, skin retraction, tissue infections, and ulcerations.

\section{Statistical analysis}

STATA software (version 12.0) was used in this metaanalysis. Univariate analysis was performed to examine the differences in keloids and hypertrophic scars between verapamil therapy and other treatment methods. Risk ratios or odds ratios estimated at $95 \%$ confidence intervals (CIs) and were used in the analysis of dichotomous variables. The random-effects model was utilized to calculate the pooled effect. In addition, chi-square test, $P^{2}$ index, and $P$-value were used to evaluate the studies. $I^{2}$ index and $P$-value were consistent in terms of heterogeneity. The fixed-effects model was employed when $I^{2}<50 \%$, whereas the random-effects model was used when $I^{2}>50 \%$. Begg's test was applied to exclude publication bias.

\section{Results}

\section{Selection and characteristics of the studies}

A total of 180 out of 227 potentially relevant studies were found irrelevant to our research (Figure 1). After initial reading of the abstracts and full texts of the remaining 47 articles, we established that 16 articles met the inclusion criteria. However, after we followed strictly the inclusion and exclusion criteria, we identified six articles ${ }^{18-23}$ that met all predetermined conditions of the study.

\section{Correlations between the groups with verapamil and nonverapamil treatments of keloids and hypertrophic scars}

The detailed information of all remaining six articles is summarized in Table 1. As outlined previously, the experiment included a verapamil group and a nonverapamil group.

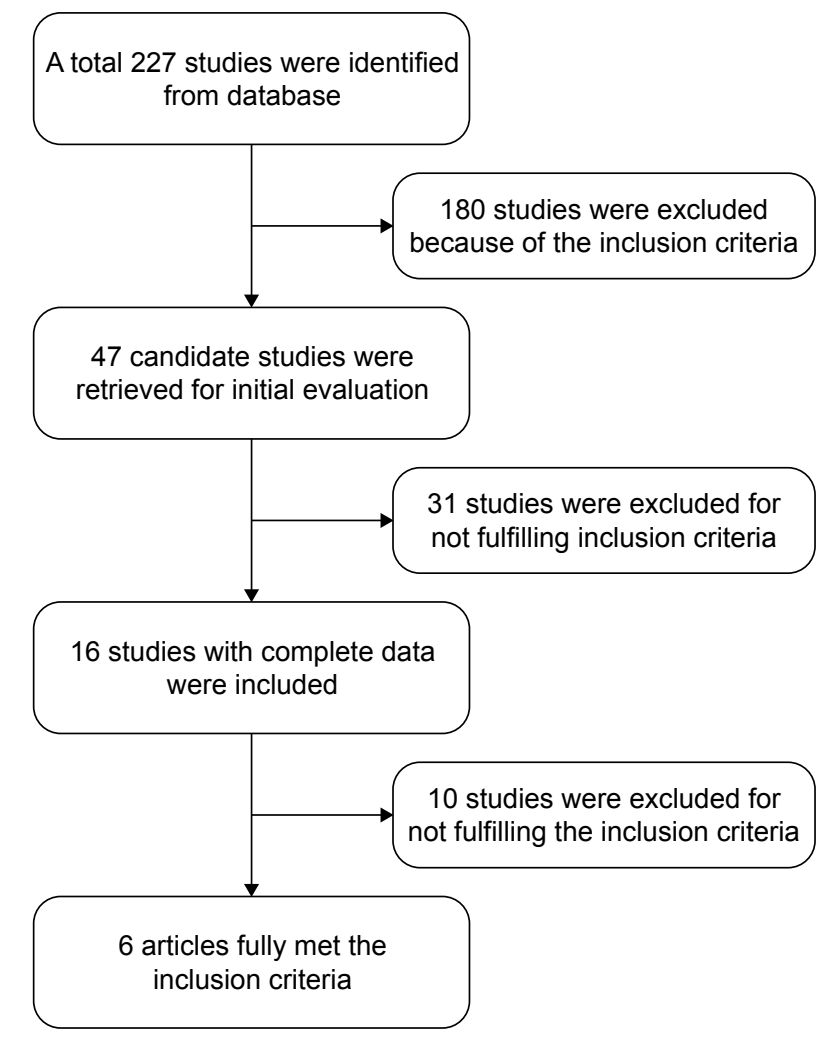

Figure I Flow diagram of the literature review and trials selection process.

The verapamil group contained 172 keloids and hypertrophic scars, with a recovery and effectivity of $54.07 \%(93 / 172)$. The recovery and effectivity in the nonverapamil group was $53.18 \%(92 / 173)$.

There was no difference between the two groups $(\mathrm{Z}=0.24$, $P=0.808$; 95\% CI: $0.77-1.26$; Figure 2) in treatments of keloids and hypertrophic scars by use of verapamil or other methods. The statistical heterogeneity was also significant $\left(I^{2}=56.4 \%, P=0.043\right)$, and the random-effects model was used in the analysis.

We also compared steroids group with the verapamil group treatment keloids and hypertrophic scars by subgroup analysis in five studies. ${ }^{18-22}$ The results showed no statistically significant difference between the subgroup analysis $(\mathrm{Z}=0.13$, $P=0.894 ; \mathrm{RR}=0.97$; $95 \%$ CI: 0.71-1.33; Figure 3), and statistical heterogeneity was significant $\left(I^{2}=64.6 \%, P=0.024\right)$. Thus, the random-effects model was used in the analysis.

Furthermore, we compared the occurrence of adverse reactions in the verapamil and the nonverapamil treatment groups in two studies. ${ }^{18,19}$ The result revealed that the verapamil group of patients had less adverse reactions than the nonverapamil group $(\mathrm{Z}=2.10, P=0.036$; $\mathrm{RR}=0.42 ; 95 \% \mathrm{CI}$ : $0.01-29.65$; Figure 4). Adverse reactions were not identified in the verapamil group. The difference was statistically significant. 
Table I Characteristics of the six studies

\begin{tabular}{|c|c|c|c|c|c|c|c|c|c|}
\hline $\begin{array}{l}\text { Study } \\
\text { (year) }\end{array}$ & $\begin{array}{l}\text { No of } \\
\text { patients }\end{array}$ & $\begin{array}{l}\text { Age } \\
\text { (years) }\end{array}$ & $\begin{array}{l}\text { Mean age } \\
\text { (years) }\end{array}$ & $\begin{array}{l}\text { Exist time } \\
\text { (years) }\end{array}$ & $\begin{array}{l}\text { Average } \\
\text { scar time } \\
\text { (years) }\end{array}$ & $\begin{array}{l}\text { Treatment } \\
\text { time }\end{array}$ & Country & Dosage & Gender \\
\hline $\begin{array}{l}\text { Tian et al }{ }^{18} \\
(2007)\end{array}$ & 32 & $2-60$ & NR & NR & NR & 4-48 weeks & $\begin{array}{l}\text { People's Republic } \\
\text { of China }\end{array}$ & $\begin{array}{l}\text { Verapamil, } 2 \mathrm{mg} / \mathrm{cm}^{2} ; \\
\text { Triamcinolone, } \\
2 \mathrm{mg} / \mathrm{cm}^{2} ; \text { Max: } 40 \mathrm{mg}\end{array}$ & M: $18 \mathrm{~F}: 14$ \\
\hline $\begin{array}{l}\text { Zhang and } \\
\text { Luo }^{19}(2006)\end{array}$ & 43 & $10-58$ & 32.7 & $0.25-8$ & 2.1 & 10 weeks & $\begin{array}{l}\text { People's Republic } \\
\text { of China }\end{array}$ & $\begin{array}{l}\text { Verapamil } 0.2-0.5 \mathrm{mg}, 10 \mathrm{mg} \\
\text { Prednisolone, NR }\end{array}$ & M: $25 \mathrm{~F}: 18$ \\
\hline $\begin{array}{l}\text { Ahuja and } \\
\text { Chatterjee }^{20} \\
(2014)\end{array}$ & 48 & $15-60$ & NR & NR & 2 & 24 weeks & India & $\begin{array}{l}\text { Verapamil, } 2.5 \mathrm{mg} / \mathrm{mL} \text {; } \\
\text { Max: I5 mL; Triamcinolone, } \\
40 \mathrm{mg} / \mathrm{mL}\end{array}$ & NR \\
\hline $\begin{array}{l}\text { Danielsen } \\
\text { et } \mathrm{a}^{21}(2016)\end{array}$ & 14 & $18-53$ & 32.1 & 12 & NR & 48 weeks & Australia & $\begin{array}{l}\text { Verapamil, } 0.5 \mathrm{mg} / \mathrm{cm} \text {, Max: } \\
2.5 \mathrm{mg} \text {; Triamcinolone } \\
\text { acetonide, } 2 \mathrm{mg} / \mathrm{cm}^{2} \text {, } \\
\text { Max: } 10 \mathrm{mg}\end{array}$ & M: 8 F: 6 \\
\hline $\begin{array}{l}\text { Bilal et a }{ }^{22} \\
(2013)\end{array}$ & 144 & $10-50$ & NR & NR & NR & 16 weeks & Pakistan & $\begin{array}{l}\text { Verapamil, } 2.5 \mathrm{mg} / \mathrm{mL} \text {; } \\
\text { Triamcinolone, } 40 \mathrm{mg} / \mathrm{mL}\end{array}$ & M: 50 F: 94 \\
\hline $\begin{array}{l}\text { Wang et } \mathrm{al}^{23} \\
(2010)\end{array}$ & 50 & NR & NR & NR & NR & 9 weeks & $\begin{array}{l}\text { People's Republic } \\
\text { of China }\end{array}$ & $\begin{array}{l}\text { Verapamil, NR Intense pulsed } \\
\text { light, NR }\end{array}$ & NR \\
\hline
\end{tabular}

Abbreviations: $F$, female; $M$, male; NR, no reference.

\section{Publication bias analysis}

State 12.0 was used in the present meta-analysis. The results of the Begg's test were utilized to evaluate publication bias that showed absence of publication bias in the meta-analysis $(\operatorname{Pr}>|z|=0.707$, continuity corrected; Figure 5). Moreover, most of the points were within the $95 \%$ CI, which further confirmed the lack of publication bias.

\section{Discussion}

Scarring is inevitable in the wound healing process, ${ }^{24}$ but pathological scar formation leads to the development of hypertrophic scars and keloids. A large number of disorders have been identified in these adverse processes, such as abnormal fibroblast proliferation, excessive deposition of extracellular matrix collagen, proteoglycans, and glycoproteins, as well as aberrant arrangement of collagen fibers. ${ }^{25}$ The clinical manifestations of patients include paresthesia accompanied with varying degrees of dysfunction, including excessive skin lesions, continuous growth of hypertrophic scars and keloids, also bumps of hypertrophic scars and keloids on the skin's surface, presence of hard texture, red-colored skin, with a formation of a sheet lump. In addition, patients had to face a series of physiological, psychological, and social issues of beauty and attractiveness. Currently, it remains

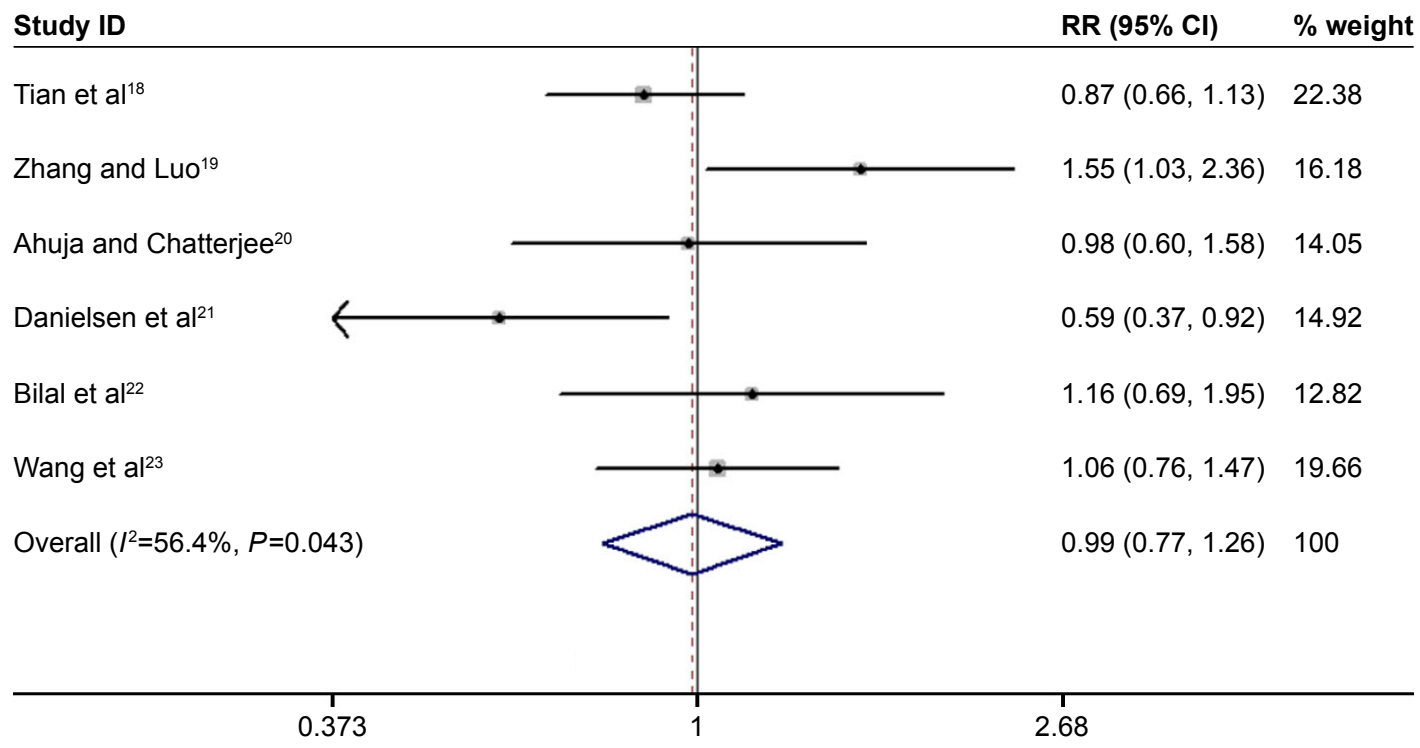

Figure 2 Forest plot of verapamil treatment group and nonverapamil treatment group analyses.

Notes: Random-effects model was used in the analysis. Squares and horizontal lines correspond to the study-specific $\mathrm{RR}$ and $95 \% \mathrm{Cl}$, respectively. The rhombus represents the summary of RR and $95 \% \mathrm{Cl}$. Weights are from random effects analysis.

Abbreviations: $\mathrm{Cl}$, confidence interval; $\mathrm{RR}$, risk ratio. 


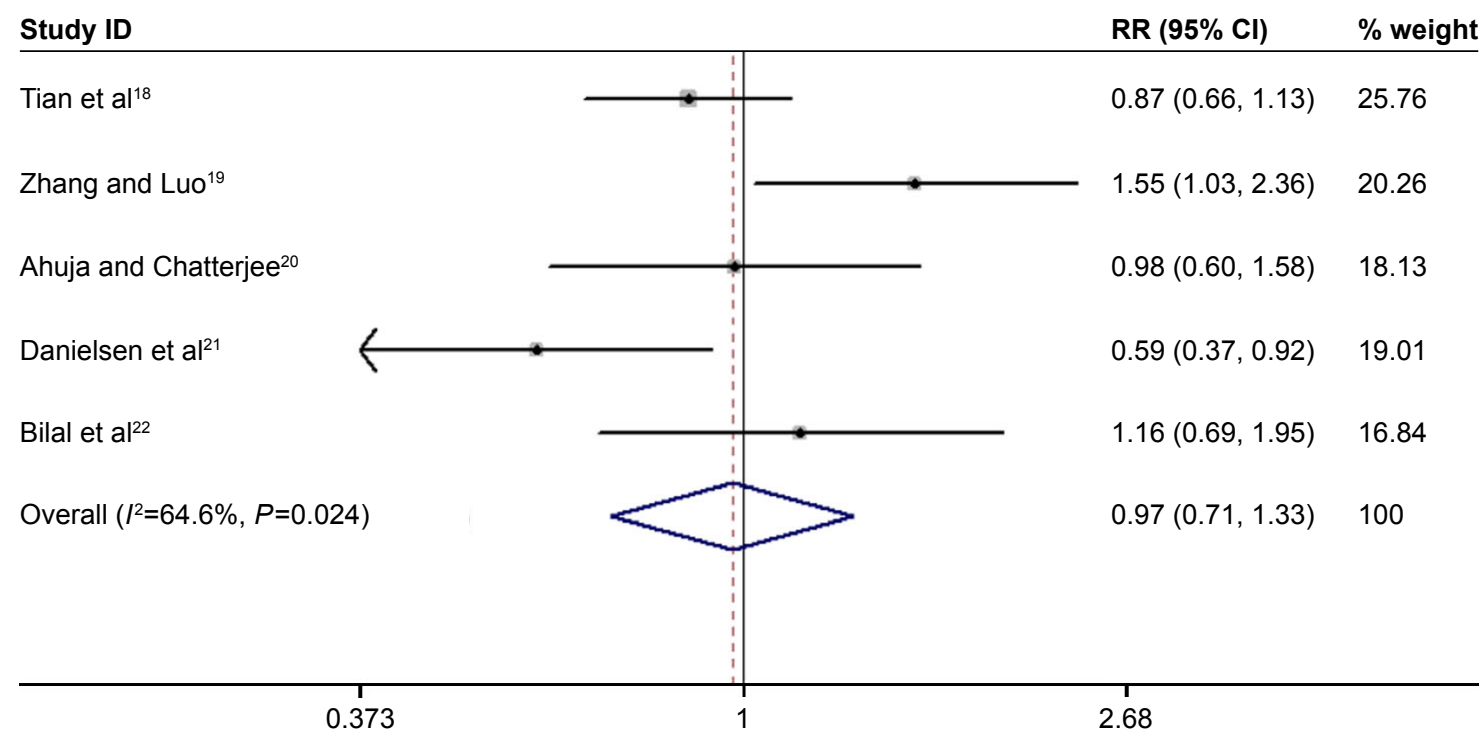

Figure 3 Forest plot of verapamil treatment group and steroids treatment group analyses.

Note: Weights are from random effects analysis.

Abbreviations: $\mathrm{RR}$, risk ratio; $\mathrm{Cl}$, confidence interval.

difficult to assess the effectiveness of the available diverse treatments for keloid and hypertrophic scars because a large number of factors can influence the efficacy of the treatment, including age, sex, and race of the patient and the anatomical position of the lesion. ${ }^{3,26-28}$

A study from 1992 was the first to report the use of the calcium channel blocker verapamil in the treatment of keloids and hypertrophic scars. ${ }^{29}$ Dong found that in a few hours after the exposure to verapamil, monolayer cultures of bipolar-shaped fibroblasts-like cells gradually become spherical. They were considered to be calcium channel blockers that after actin filaments, depolymerization led to changes in cell morphology, and eventually induced the formation of a more circular shape of fibroblasts and easy to change shapes. Then, they cultivate a three-dimensional cell after surgical resection of six patients hypertrophic scar fibroblasts.
The result shows that calcium channel blockers verapamil on three-dimensional culture system increased dose dependently inhibit the contraction, and culture system allows hypertrophic scar cell morphological changes. Therefore, verapamil inhibited the hypertrophic scar fibroblasts-cultured three-dimensional model of the contraction. The mechanism of action of calcium channel blockers may be related to the suppression of the variations in intracellular calcium ion concentration and inhibition of collagen synthesis and then suppression of hypertrophic scars and keloids progress. ${ }^{30}$

In animal experiments, the treatment with verapamil has been revealed to influence the scarring function. ${ }^{31}$ To experimentally investigate the effects of verapamil therapy, the authors established a hypertrophic scar model confirming that the local injection of verapamil reduced scar collagen content and the resulting scar atrophy. In 1994, Lee et $\mathrm{al}^{32}$ was the

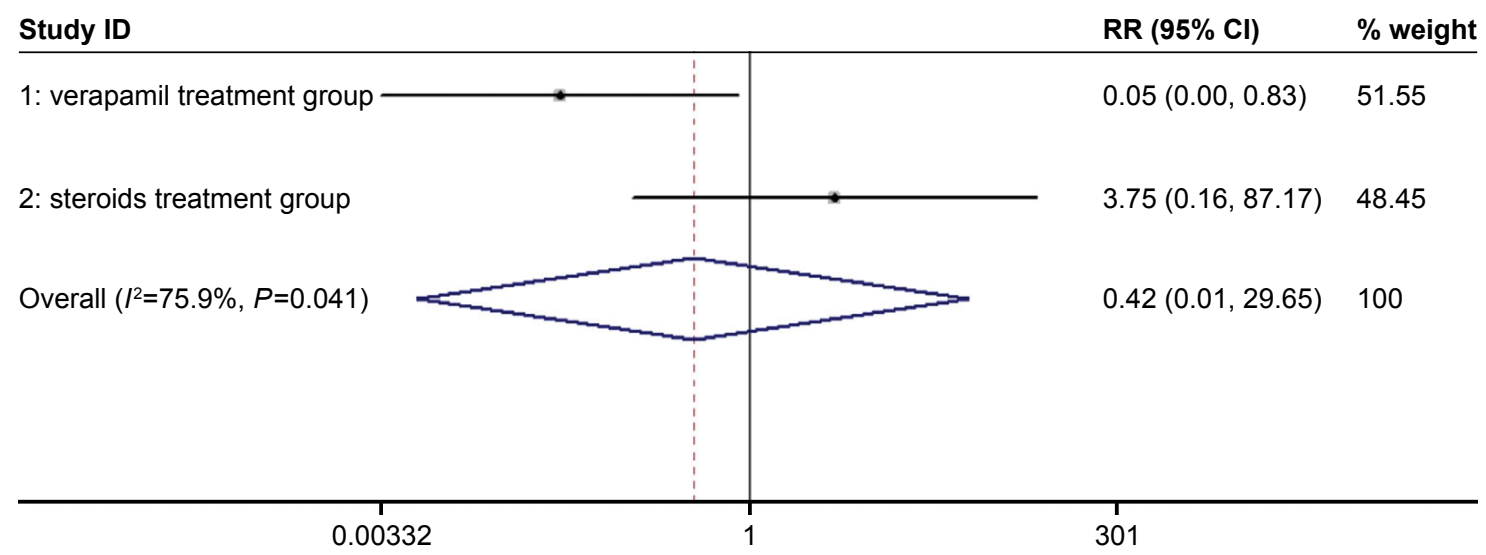

Figure 4 Forest plot of the analyses of the adverse reactions in the verapamil treatment group and steroids treatment group.

Note: Weights are from random effects analysis.

Abbreviations: $\mathrm{RR}$, risk ratio; $\mathrm{Cl}$, confidence interval. 


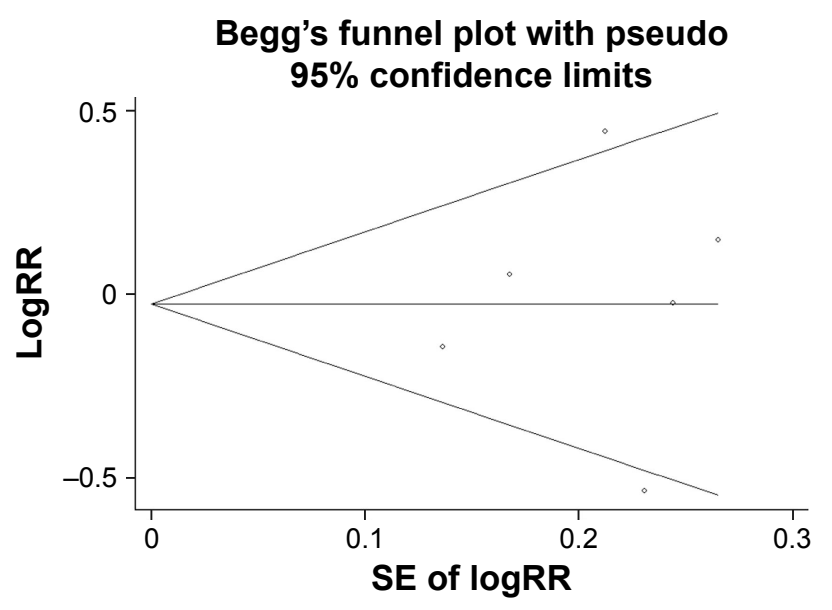

Figure 5 Begg's test results of the publication bias. Abbreviations: RR, risk ratio; SE, standard error.

first to report the use of verapamil in the clinical treatment of post-burn hypertrophic scars. At present, an ever-increasing body of evidence has confirmed that verapamil injection therapy is a quick and effective option in scar treatment. .,33 $^{8}$

Corticosteroid is one of the first drugs used in the treatment of scars. Since the beginning of 1960, corticosteroids have been applied in the therapy of keloid and hypertrophic scars. ${ }^{34}$ The most common and popular corticosteroid utilized for the treatment of pathological scars is triamcinolone acetonide, which continues to play an important part in the management of keloids. ${ }^{35}$ The most common corticosteroid which is used in keloid treatment was triamcinolone acetonide. It has to be a popular treatment for pathological scars, and this treatment continues to play an important role in the management of keloids. ${ }^{36,37}$

Another important options for the treatment of keloids and hypertrophic scars include the administration of 5-fluorouracil, ${ }^{38}$ bleomycin, ${ }^{39}$ interferon, ${ }^{40}$ and cryotherapy. ${ }^{41}$

In this meta-analysis, we did not find differences between the application of verapamil and nonverapamil used in the treatment of keloids and hypertrophic scars. Our findings indicate that the use of verapamil and the employment of other methods, and more specifically the utilization of corticosteroids, exert identical therapeutic effects in keloids and hypertrophic scars treatment. Nonetheless, compared with steroids, less adverse reactions and side effects were manifested in the verapamil injection group.

There are also studies researching the influence of the combination of verapamil treatment with nonverapamil methods for treating keloids and hypertrophic scars. ${ }^{23}$ Studies have shown that verapamil combination with other methods has a better therapeutic effect in keloids and hypertrophic scar treatment. Therefore, the combined therapy of keloids and hypertrophic scars could be considered a better option to the conventionally used treatments. Nevertheless, in spite of the considerable application prospects, more comprehensive future research is required to confirm the effects and feasibility of this therapeutic choice.

\section{Limitations}

Several limitations of our study should be acknowledged when interpreting the results. First, the articles and data were not too many according to our inclusion criteria; this probably caused publication bias. Begg's test was applied to exclude publication bias. Second, due to uncontrolled confounding factors and selection bias, there produced some heterogeneity in the study. We adopted random-effects model to solve this problem. Third, only articles published and written in English and Chinese were included this meta-analysis, which might have resulted in some degree of publication bias. However, we did not find significant publication bias. So, it indicated that potential publication bias has done no noticeable harm for the study.

\section{Conclusion}

In this meta-analysis, we did not find statistically significant difference between the therapeutic effects in the treatment of keloids and hypertrophic scars in the verapamil group and the nonverapamil group derived from the studies analyzed. The patients in the subgroup, verapamil injection treatment group, had a lower incidence of adverse reactions and side effects compared with the group in which steroids were used. In conclusion, verapamil could act as an effective alternative modality in the prevention and treatment of keloid and hypertrophic scars. Nevertheless, these findings require a large number of studies to be confirmed in the treatment of keloids and hypertrophic scars.

\section{Acknowledgments}

This research was funded by National Natural Science Foundation of China (81060233); Industrial Technology Research and Development project of Jilin Province (2013C034); Scientific Research project of Yanbian University (601010029).

\section{Disclosure}

The authors report no conflicts of interest in this work.

\section{References}

1. Rekha A. Keloids - a frustrating hurdle in wound healing. Int Wound J. 2004;1(2):145-148.

2. Diegelmann RF, Evans MC. Wound healing: an overview of acute, fibrotic and delayed healing. Front Biosci. 2004;9:283-289.

3. Huang C, Murphy GF, Akaishi S, Ogawa R. Keloids and hypertrophic scars: update and future directions. Plast Reconstr Surg Glob Open. 2013; 1(4):e25. 
4. Ogawa R. Mechanobiology of scarring. Wound Repair Regen. 2011; 19(Suppl 1):s2-s9.

5. Majewski S, Bosch FX, Dillner J, et al. The impact of a quadrivalent human papillomavirus (types $6,11,16,18$ ) virus-like particle vaccine in European women aged 16 to 24. J Eur Acad Dermatol Venereol. 2009; 23(10):1147-1155.

6. Marinović B, Sterry W, Paus R, Burgdorf W. Dermatology - Thieme Clinical Companions, Georg Thieme Verlag, Stuttgart, New York, 2006 Format: hard cover, one volume; 754 pages, 345 illustrations, 28 authors ISBN 13-135911-0. Acta Dermatovenerol Croat Adc. 2008;16(3).

7. Burgdorf W, Plewig G, Wolff HH, Landthaler M. Braun-Falco's Dermatology. Berlin, Heidelberg: Springer; 2009.

8. Berman B, Maderal A, Raphael B. Keloids and hypertrophic scars: pathophysiology, classification, and treatment. Dermatol Surg. Epub 2016 Jun 24.

9. Boggio RF, Boggio LF, Galvão BL, Machado-Santelli GM. Topical verapamil as a scar modulator. Aesthetic Plast Surg. 2014;38(5):968-975.

10. Copcu E, Sivrioglu N, Oztan Y. Combination of surgery and intralesional verapamil injection in the treatment of the keloid. J Burn Care Rehabil. 2004;25(1):1-7.

11. Han AC, Deng JX, Huang QS, et al. Verapamil inhibits scar formation after peripheral nerve repair in vivo. Neural Regen Res. 2016;11(3): 508-511.

12. Giugliano G, Pasquali D, Notaro A, et al. Verapamil inhibits interleukin-6 and vascular endothelial growth factor production in primary cultures of keloid fibroblasts. Br J Plast Surg. 2003;56(8):804-809.

13. Robles DT, Moore E, Draznin M, Berg D. Keloids: pathophysiology and management. Dermatol Online J. 2007;13(3):9.

14. Eng TY, Boersma MK, Fuller CD, et al. The role of radiation therapy in benign diseases. Hematol Oncol Clin North Am. 2006;20(2):523-557.

15. Asilian A, Darougheh A, Shariati F. New combination of triamcinolone, 5-Fluorouracil, and pulsed-dye laser for treatment of keloid and hypertrophic scars. Dermatol Surg. 2006;32(7):907-915.

16. Kono T, Ercocen AR, Nakazawa H, Honda T, Hayashi N, Nozaki M. The flashlamp-pumped pulsed dye laser $(585 \mathrm{~nm})$ treatment of hypertrophic scars in Asians. Ann Plast Surg. 2003;51(4):366-371.

17. Skaria AM. Prevention and treatment of keloids with intralesional verapamil. Dermatology. 2004;209(1):60-62.

18. Tian C, Liu H, Peng HT. Comparison the effects of verapamil and triamcinolone in hypertrophic scars treatment. Western Med. 2007; 19(1):87.

19. Zhang L, Luo JH. Clinical observation on verapamil local injection treatment in keloid. China J Leprosy Skin Dis. 2007;(6):481.

20. Ahuja RB, Chatterjee P. Comparative efficacy of intralesional verapamil hydrochloride and triamcinolone acetonide in hypertrophic scars and keloids. Burns. 2014;40(4):583-588.

21. Danielsen PL, Rea SM, Wood FM, et al. Verapamil is less effective than triamcinolone for prevention of keloid scar recurrence after excision in a randomized controlled trial. Acta Derm Venereol. 2016;14(3):265-287.

22. Bilal M, Tahmeedullah, Irfanullah, Shah SA. Clinical outcome of intralesional corticosteroid versus intralesional Verapamil in the treatment of post burn Keloid scars of the head and neck region. PakJ Surg. 2013;29(4):263-268

23. Wang LN, Wu ZT, Fan KW, et al. To experience craniofacial trauma with early intense pulsed light combined with anti-scarring treatment of verapamil. Twentieth China-Japan Symposium on Plastic Surgery, 2010.
24. Stroncek JD, Reichert WM. Overview of wound healing in different tissue types. In: Reichert WM, editor. Indwelling Neural Implants: Strategies for Contending with the In Vivo Environment. Boca Raton, FL: CRC Press/Taylor \& Francis; 2008. Available from: https://www. ncbi.nlm.nih.gov/books/NBK3938/

25. Breton L, Liviero C, Fagot D. Skin toning by stimulating collagen synthesis/proliferation of dermal fibroblasts: US, US $6147121 \mathrm{~A}[\mathrm{P}]$. 2000.

26. Azad SM, Gerrish J, Dziewulski P, Azad SM, Gerrish J, Dziewulski P. Hypertrophie scars and keloids: an overview of the aetiology and management. Hand Ther. 2000;5(5):16-20.

27. Ogawa R. The most current algorithms for the treatment and prevention of hypertrophic scars and keloids. Plast Reconst Surg. 2010; 125(2):1131-1132.

28. Klinger M, Marazzi M, Vigo D, Torre M. Fat injection for cases of severe burn outcomes: a new perspective of scar remodeling and reduction. Aesthetic Plast Surg. 2008;32(32):465-469.

29. Dong H, Earle ML, Jiang Y, Loutzenhiser KA, Triggle CR. Cardiovascular effects of CPU-23, a novel L-type calcium channel blocker with a unique molecular structure. Br J Pharmacol. 1997;122(7):1271-1278.

30. Wang Zhen, Lu KH, Guo SZ, et al. Inhibition of hypertrophic scar derived fibroblast-populated collagen lattice contraction by calcium antagonist. Negative. 1999;20(7):559-562.

31. You WT, Qin ZL, Niu XT. The effect of intralesional verapamil on the hypertrophic scar in rabbit ear. Chinese J Med Aesthetic Cosmetol. 2000;4(5):252-255.

32. Lee RC, Doong H, Jellema AF. The response of burn scars to intralesional verapamil. Report of five cases. Arch Surg. 1994;129(1):107-111.

33. Wang R, Mao Y, Zhang Z, Li Z, Chen J, Ying C. Role of verapamil in preventing and treating hypertrophic scars and keloids. Int Wound $J$. 2016;13(4):461-468.

34. Roques $\mathrm{C}$, Téot $\mathrm{L}$. The use of corticosteroids to treat keloids: a review. Int J Low Extrem Wounds. 2008;7(3):137-145.

35. Ketchum LD, Smith J, Robinson DW, Masters FW. The treatment of hypertrophic scar, keloid and scar contracture by triamcinolone acetonide. Plast Reconstr Surg. 1966;38(3):209-218.

36. Gupta S, Sharma VK. Standard guidelines of care: keloids and hypertrophic scars. Indian J Dermatol Venereol Leprol. 2011;77(1):94-100.

37. Chen MA, Davidson TM. Scar management: prevention and treatment strategies. Curr Opin Otolaryngol Head Neck Surg. 2005;13(4): $242-247$.

38. Manuskiatti W, Fitzpatrick RE. Treatment response of keloidal and hypertrophic sternotomy scars: comparison among intralesional corticosteroid, 5-fluorouracil, and 585-nm flashlamp-pumped pulsed-dye laser treatments. Arch Dermatol. 2002;138(9):1149-1155.

39. Payapvipapong K, Niumpradit N, Piriyanand C, Buranaphalin S, Nakakes A. The treatment of keloids and hypertrophic scars with intralesional bleomycin in skin of color. $J$ Cosmet Dermatol. 2015;14(1): $12-31$.

40. [No author]. Use intralesional interferon gamma for keloid and hypertrophic scars. Inpharma Weekly. 1991;769(1):12.

41. Jaros E, Príborský J, Klein L. [Treatment of keloids and hypertrophic scars with cryotherapy]. Neurosurgery. 1999;54(54):1436-1440. Czech
Therapeutics and Clinical Risk Management

\section{Publish your work in this journal}

Therapeutics and Clinical Risk Management is an international, peerreviewed journal of clinical therapeutics and risk management, focusing on concise rapid reporting of clinical studies in all therapeutic areas, outcomes, safety, and programs for the effective, safe, and sustained use of medicines. This journal is indexed on PubMed Central, CAS,

\section{Dovepress}

EMBase, Scopus and the Elsevier Bibliographic databases. The manuscript management system is completely online and includes a very quick and fair peer-review system, which is all easy to use. Visit http://www.dovepress.com/testimonials.php to read real quotes from published authors. 